\title{
ESTUDOS
}

\section{Interdisciplinaridade e transversalidade mediante projetos temáticos}

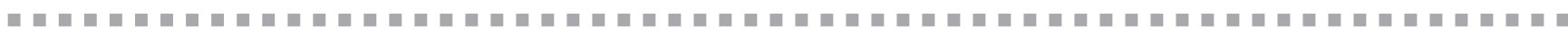
Silvia Elizabeth Moraes

Palavras-chave:

interdisciplinaridade;

transversalidade; escola

fundamental; projetos temáticos.

\section{Resumo}

Sugere a prática da interdisciplinaridade e da transversalidade na escola fundamental, por meio de projetos temáticos. A interdisciplinaridade é vista como uma abordagem epistemológica que questiona a visão disciplinar, fragmentada, do conhecimento. A transversalidade refere-se a um recurso pedagógico cujo intuito é ajudar o/a aluno/a a adquirir uma visão mais compreensiva e crítica da realidade assim como sua inserção e participação nessa realidade. Como fundamentação teórica, utilizam-se a teoria das Inteligências Múltiplas, de Howard Gardner, e a teoria dos significados da vida humana, de Philip Phenix, e exemplifica-se a pedagogia de projetos como prática curricular interdisciplinar e transversal. Propõe-se, também, uma forma de avaliação construída coletivamente pelos participantes dos projetos temáticos.

\section{O currículo e a evolução do conhecimento}

Os conceitos de interdisciplinaridade e transversalidade, que vêm revolucionando o currículo da escola fundamental, resultam da evolução do conhecimento na civilização ocidental e têm por finalidade modificar a visão tradicional de currículo, que se caracteriza pela fragmentação, linearidade, alienação e estímulo ao individualismo no trabalho escolar. A idéia por trás da interdisciplinaridade e transversalidade é construir um currículo onde possamos, junto com o aprendizado científico, favorecer o inesperado, o criativo, e o aperfeiçoamento de atitudes e valores que transcendam barreiras de raça, classe, religião, sexo ou política.
A interdisciplinaridade e a transversalidade foram introduzidas na escola brasileira pelos Parâmetros Curriculares Nacionais (PCN), em 1996. Embora tenham os PCN recebido várias críticas por parte de alguns teóricos do currículo - consideramno uma proposta pouco discutida, muito detalhada, fechada, longa e difícil de assimilar em todo seu conteúdo -, têm sido também muito bem aceitos pelos professores, o que me foi constatado por pesquisa realizada na rede pública estadual paulista. ${ }^{1}$

A adoção de um currículo nacional para a escola fundamental apresenta nitidamente dois aspectos conflitantes. Se por um lado temos o perigo de cair no autoritarismo da imposição de um "conhecimento oficial" (Apple, 1993a, 1993b) que

\footnotetext{
1 Análise de currículo da rede pública de São Carlos e Interdisciplinaridade na escola fundamental - 1996-1999. pesquisa de recém-doutor (CNPq), cujas conclusões constam do livro Leitura e constam do livro Leitura e
Interdisciplinaridade-tecendo redes nos projetos da escola (Kleiman, Moraes, 1999).
} 
reflete o "arbitrário cultural" (Bourdieu; Passeron, 1982) de grupo ou grupos no exercício do poder, por outro lado faz-se necessário reformular a escola não somente para estar em sintonia com as novas tecnologias e modalidades de aprender, como também, através da discussão do multiculturalismo, para definir características fundamentais que diferenciem os povos, a fim de escaparmos da uniformização cultural com a qual nos ameaça a globalização (Moraes, 2000).

Vários outros países - Inglaterra, Estados Unidos, Chile, África Ocidental (Ghana, Sierra Leone, Libéria, Nigéria e Gambia), Malta e Austrália - também vêm trabalhando no sentido de delinear currículos nacionais e de, assim como os PCN, inserir os temas transversais de ética, direitos humanos, respeito ao meio ambiente, cidadania e multiculturalismo. Portanto, o que temos atualmente é um conjunto de tentativas por parte da escola fundamental de, por intermédio do seu currículo,

[...] adaptar-se à nova visão interdisciplinar do conhecimento; delimitar fronteiras culturais já que as políticas e geográficas foram eliminadas pela informação tecnológica e pelo progresso nas comunicações e transportes; e, recuperar as discussões sobre ética e moral que foram afastadas do âmbito da ciência durante a modernidade (Moraes, 2000, p. 206).

Definimos interdisciplinaridade como uma abordagem epistemológica que nos permite ultrapassar as fronteiras disciplinares e nos possibilita tratar, de maneira integrada, os tópicos comuns às diversas áreas. O intuito da interdisciplinaridade é superar a excessiva fragmentação e linearidade no currículo. Mediante o estudo de temas comuns, estabelece-se um diálogo entre disciplinas, embora sempre considerando a especificidade de cada área, com seu saber acumulado que deriva do olhar especializado. A excessiva disciplinaridade e linearidade colocam o conhecimento numa camisa-de-força e não levam em conta o fato de que aprendemos estabelecendo relações entre assuntos, entre situações vividas ou imaginadas, entre coisas lidas e ouvidas, emoções, sensações tácteis, auditivas, visuais, gustativas, olfativas, elementos estes que não se submetem à tirania do tempo ou do espaço físico da sala de aula, das fronteiras arbitrárias das disciplinas ou das unidades de um livro.
Definimos transversalidade como um recurso pedagógico cujo intuito é ajudar o/ a aluno/a a adquirir uma perspectiva mais compreensiva e crítica da realidade social, assim como sua inserção e participação nessa realidade. Contrapõe-se à visão alienada e individualista do conhecimento e, através da inserção de temas transversais, relaciona os conteúdos com o contexto que os cerca e ignora ainda mais as barreiras disciplinares.

O transversal é extremamente político, no sentido dado por Hanna Arendt: o ato de falar e interagir um com o outro no espaço público, locus ideal para o exercício da liberdade humana. O transversal nos obriga a situar os conceitos (Apple, 1981), ou seja, explicar as reflexões latentes ou codificadas dos modos de produção material, valores ideológicos, relações de classe e estruturas de poder social - racial, sexual, político-econômico - no processo de conscientização das pessoas numa situação histórica ou socioeconômica determinada. O transversal faz-nos aliar aos conceitos as maneiras como as instituições, pessoas e modos de produção, distribuição e consumo são organizados e controlados e dominam a vida cultural.

A finalidade última dos temas transversais é, portanto, desenvolver nos alunos a capacidade de posicionar-se diante das questões que interferem na vida coletiva e que distorcem a visão do homem com relação à natureza. Pela adoção da transversalidade, o currículo arrola a si a responsabilidade de contribuir para o desenvolvimento do universalismo normativo (Habermas, 1995): o aperfeiçoamento das instituições políticas internacionais, para que sejam capazes de enfrentar a universalização técnica e procurar soluções políticas para os problemas globais.

$\mathrm{Na}$ prática, a interdisciplinaridade e a transversalidade se fundem, se entrelaçam, numa rede de relações e conexões que ligam os conteúdos disciplinares uns aos outros, inserem estes conteúdos na realidade e no contexto que nos cerca. As palavras-chave são integração, não-linearidade, contextualização, participação, visão crítica e trabalho coletivo. Tais mudanças requerem uma administração autônoma e democrática cujo elemento fundamental seja um projeto pedagógico que incorpore uma visão de democracia e cidadania (Moraes, 2003a; Moraes, 2003b).

Para entender como chegamos a tais mudanças em nossa racionalidade - aqui 
definida como a aquisição e o uso do conhecimento (Habermas, 1984) -, vamos examinar brevemente o período situado entre Newton (1643-1727), com seu universo estável de planetas girando em torno do Sol em perfeita harmonia, e o gigante em expansão que temos hoje diante de nós, onde cada dia descobrimos novos planetas, novas galáxias, matérias desconhecidas perdidas nesse imenso espaço dentro do qual somos pequeninos grãos de areia.

Grosso modo, dividiremos a civilização ocidental em três épocas - pré-moderna, moderna e pós-moderna - e, dentro de cada uma delas, examinaremos brevemente as concepções vigentes de Universo, Estado, Ciência, Natureza, Futuro, Homem, Arte e Cultura, relevantes para a discussão em pauta, e, finalmente, como conclusão e como fruto de todas essas concepções, a visão de Currículo e Aprendizagem.

Essas épocas não podem ser consideradas como fases da nossa civilização, que se sucederam uma após a outra; são apenas termos utilizados para nos referirmos ao conjunto de mudanças radicais que ocorreram, continuam ocorrendo no pensamento do homem ocidental e vêm influenciando o currículo da escola. No mundo há povos que ainda vivem na prémodernidade; no Brasil, por exemplo, experimentamos as três fases ao mesmo tempo: enquanto alguns têm acesso à tecnologia mais avançada - ou seja, vivem na pósmodernidade -, temos populações que ainda nem conhecem a luz elétrica (e às vezes nem estão interessados) ou que nunca se depararam com um livro ou um jornal. Por isso, vamos nos referir a pré-modernidade, modernidade e pós-modernidade tendo em mente o nosso passado e o nosso presente em ampla e profunda transição no que concerne à escola fundamental.

Na pré-modernidade, a Igreja Católica exercia total domínio sobre o pensamento ocidental; na ciência, a Terra era considerada plana, e o homem, o centro do Universo. Quando o astrônomo e físico italiano Galileu (1564-1642) ousou discordar de tal teoria, quase acabou na fogueira, queimado pela Inquisição. A concepção de indivíduo tal como a que temos hoje - um ser dotado de autonomia de pensamento, liberdade de expressão e de crença - ainda não havia surgido, sendo os povos e as pessoas submissos à imposição da Igreja e considerados incapazes e sem autonomia de pensamento e de estilo de vida (Santos Filho,
2000). Na arte preponderavam as representações das figuras religiosas - os santos, a Virgem Maria, Jesus Cristo -, e nas instituições de ensino difundiam-se somente as verdades estabelecidas pela Igreja.

O projeto da modernidade tomou força durante o século 18 e continuou por quase todo o século 19, chegando-nos ao século 20, à Revolução da Informática. Para Habermas (1983), o projeto da modernidade pode ser visto como um extraordinário esforço intelectual dos pensadores iluministas para desenvolver a ciência objetiva, as leis universais e a arte autônoma. O domínio científico da natureza prometia ausência da escassez, da necessidade e da arbitrariedade das calamidades naturais. O desenvolvimento de formas racionais de organização social e de modos de pensamento prometia a libertação da irracionalidade do mito, da religião, da superstição, e do uso arbitrário do poder.

Na visão de universo temos uma grande diferença: já não se podiam calar os cientistas, com seus telescópios perscrutando o infinito e descobrindo como o universo se organiza. Isaac Newton (1642-1727) mostrou o papel da força da gravidade no universo: que a mesma força que puxa um objeto para a Terra mantém a Lua em órbita e que a força gravitacional do Sol mantém os planetas girando em suas órbitas. O pensamento newtoniano é um dos fundamentos sobre os quais se baseia o currículo moderno, que continua vigente e resistindo às inovações. Correlações diretas podem ser feitas entre as noções de um currículo disciplinado, com seus fins preestabelecidos, e a idéia de Newton de um universo estável com os planetas girando em torno do Sol em perfeita harmonia. Harmonia é definitivamente um conceito moderno, e a perturbação (inquietação) não é vista como um ingrediente necessário ou até desejável.

$\mathrm{O}$ indivíduo passou a ser a figura fundamental na sociedade moderna, e o individualismo, a marca da modernidade. A emancipação do homem como indivíduo é realização única da civilização ocidental, talvez até sua principal característica. Na Idade Média, os direitos e as responsabilidades do indivíduo eram determinados pelo seu lugar numa sociedade extremamente estratificada e hierarquicamente organizada, baseada na aquiescência e conformidade. Com a comercialização e urbanização da Europa, o sistema medieval teve de ser acomodado às novas 
necessidades dos dirigentes nacionais e às demandas de uma indústria e comércio em expansão. A revolta da burguesia contra os monarcas absolutistas trouxe mudanças que moldaram a sociedade ocidental: o sistema feudal foi destruído, a aristocracia perdeu seus privilégios, tiranos foram desafiados e derrubados, surgiu o governo representativo e os liberais desenvolveram a doutrina dos direitos individuais. Na modernidade foram constituídas as nações-Estado: estabeleceram-se limites geográficos, formaramse as constituições de vários países e o homem ocidental adquiriu sua cidadania no sentido político e cultural.

O Estado assumiu a posição que antes pertencia à Igreja e colocou-se como única instância capaz de mediar a contraditoriedade do ser humano, dominado pelos interesses individuais, pelos afetos e paixões. O poder buscou justificar-se na Razão. O Estado racional acompanhou, passo a passo, o processo de secularização da autoridade política (Goergen, 2000). Podemos dizer que a modernidade foi o triunfo da Razão e do Indivíduo.

$\mathrm{Na}$ arte e na cultura, a modernidade valorizou a produção de elite: cultura, arte e música eruditas. Desprestigiou-se e desqualificou-se o popular (Santos Filho, 2000). No Brasil adotamos os ideais da cultura européia, especialmente a francesa. Imitávamos tudo: vestimenta o centro da moda era Paris, e vários termos em francês foram incorporados ao vocabulário ao falarmos de moda, como, por exemplo, changeant, para designar um tecido furta-cor, pied de poule, um tipo de estampa com a forma de um pé de galinha, voile, que designa um tecido bem fino; música - o chic era tocar Débussy, Chopin, Beethoven no piano; comida - até hoje os restaurantes requintados têm seus menus em francês; educação - as jovens de famílias ricas iam para o internato nos colégios Sacré Cœur de Jésus, Sion ou Assunción, onde falavam e rezavam em francês; literatura lia-se Balzac, Voltaire, Chateubriand, Victor Hugo; cultura - ia-se ao teatro para escutar canto lírico. A desvalorização da cultura autóctone teve conseqüências diretas na formulação do currículo brasileiro, permeado de idéias importadas e transmitindo subjacentemente um discurso de colonizado.

A ciência, para o filósofo moderno, era vista como atividade auto-referente, nobre, desinteressada, cuja função era romper com o mundo das trevas, do senso comum e das crenças tradicionais, contribuindo, assim, para o desenvolvimento moral e espiritual da humanidade. Nação e ciência caminhavam juntas. Abundavam doutrinas de igualdade, liberdade, fé na inteligência humana (uma vez permitidos os benefícios da educação) e razão universal (Moraes, 2000). "A idéia de modernidade", diz Touraine (1995, p.18), "substitui Deus no centro da sociedade pela ciência, deixando as crenças religiosas para a vida privada".

Mas essa mesma ciência que nos trouxe as vacinas, a penicilina e inúmeros avanços no campo dos transportes, das comunicações, trouxe-nos também a bomba atômica, os campos de concentração, o nazismo, duas guerras mundiais, produziu armas sofisticadas com imenso poder letal e infringiu visíveis danos à natureza. Portanto, a ciência tanto contribuiu para a vida quanto para a morte, e essa é uma das principais razões pelas quais vemos o projeto da modernidade entrar em crise.

Na pós-modernidade, nossa visão de universo simples, estável e eterna do modernismo newtoniano passa a ser complexa, caótica, perturbadora. Para Marcelo Gleiser (Folha de S. Paulo, 22/3/1998), "em menos de 70 anos, passamos de um pequeno universo, aconchegante e familiar, a um gigante em expansão, misterioso e indiferente à condição humana". Hoje sabemos que existem centenas de bilhões de outras galáxias, cada uma delas com milhões de estrelas. Postamo-nos diante de grandes indagações: estaremos sozinhos nessa imensidão? Existe algo além do universo? Ele tem fim? Algum dia teve começo? Bilhões de dólares são investidos na busca de outros mundos, de outros planetas. A incerteza transforma a visão de currículo, pois não podemos mais transmitir ao aluno a verdade científica como pensávamos fazer.

O Estado, tal qual o vimos nascer na modernidade, é questionado: suas atribuições e responsabilidades vêm sendo rediscutidas, e seu papel é a grande interrogação para a qual procuramos resposta. Prega-se o Estado minimalista e enfatizase a economia de mercado como a chave para a liberdade política e econômica. No caso brasileiro, o funcionamento do mercado tem exibido um elevado potencial de perversidade.

Quanto à ciência moderna, vista por Toulmin (1982) como uma ciência sem humanidade - sem valores, propósitos, crenças -, 
é substituída pela ciência pós-moderna, que ensaia timidamente aliar seus fins à discussão de novas regras, de códigos de Ética. Estamos todos preocupados com os rumos da ciência: devemos clonar seres humanos? Devemos interferir nos genes para criar seres mais inteligentes, mais bonitos? O que fazer com a possibilidade de escolhermos o sexo dos nossos filhos que ainda estão por nascer? Como podemos reverter o quadro de destruição ambiental causado pela ciência, ou seja, como usar a ciência para desfazer o mal que ela própria causou?

A reflexão ética permite pensar alternativas e traz à luz a discussão sobre a liberdade de escolha. Trata-se aqui de considerar o sentido ético da convivência humana em suas várias dimensões: o ambiente, a cultura, a sexualidade, a saúde. A ética interroga a legitimidade de práticas e valores consagrados pela tradição e pelo costume. Abrange tanto a crítica das relações entre os grupos, dos grupos nas instituições e diante delas, quanto a dimensão das ações pessoais. $\mathrm{O}$ individualismo, a marca da modernidade, está gradualmente sendo substituído pelo espírito coletivo. Temos que encontrar soluções comuns para os grandes problemas que nos afligem - a questão ambiental, a violência, os conflitos étnicos e religiosos. Para isso estão sendo criados os grandes fóruns internacionais, e o homem une-se em movimentos de solidariedade.

No âmbito da natureza, a palavra-chave é Ecologia. É o fim da utopia do domínio do homem sobre a natureza. Chegamos finalmente à conclusão de que, se não entabularmos um novo diálogo com a natureza, não sobreviveremos. Já sabemos que não podemos impensadamente desviar o curso de um rio para construir uma hidroelétrica; precisamos primeiramente minimizar os efeitos dessa medida sobre a fauna e a flora do lugar. Alguns teóricos vão mais longe ainda e pregam uma reação à fragmentação do saber reunificando-o pela questão ambiental.

Quanto à música, Beethoven é ouvido junto com o forró, pagode, samba e música sertaneja. Para Featherstone (2000, p. 74), cada vez mais achamos argumentos de que as distinções culturais e julgamentos de gostos são arbitrários. "Não há nada intrinsecamente melhor em Beethoven, Shakespeare, ou na cultura erudita do que na cultura popular."
Os produtos que circulam entre os países dos blocos econômicos trazem consigo hábitos, tradições, palavras, receitas culinárias, danças e canções. O homem não é mais visto como um cidadão nacional, mas sim como um cidadão do mundo. $\mathrm{O}$ documento que indicava uma nacionalidade, o passaporte, em muitos lugares já está obsoleto. Nós aqui do Mercosul já podemos viajar para o Paraguai, Argentina, Bolívia, Colômbia e outros países do Cone Sul somente com nossa carteira de identidade. O mesmo acontece na Comunidade Européia, onde as pessoas transitam de um país para o outro sem restrições de fronteiras.

Passamos por uma nova era quando a produção da cultura tornou-se integrada à produção de mercadorias em geral: a frenética urgência de fabricarmos bens com aparência cada vez mais nova. As lutas antes travadas na arena exclusiva da indústria se espalharam para a cultura, algo que envolve uma mudança de hábitos e atitudes de consumo até mesmo nas definições estéticas. A moda, os filmes, a promoção de eventos multimídia, espetáculos grandiosos atestam o caráter enganoso e efêmero das formas culturais submissas à publicidade, a arte oficial do capitalismo (Harvey, 1994, in Moraes, 2000). A partir de enormes campanhas publicitárias, nascem artistas, pintores, poetas, cantores, muitos de qualidade duvidosa. Os shows nas campanhas políticas vendem uma imagem do candidato e não um programa de governo. É a Era do Marketing.

"A história da modernidade é a história da ruptura lenta mas inelutável entre o indivíduo, a sociedade e a natureza", diz Touraine (1995, p. 162). O currículo moderno retrata esta ruptura através da compartimentalização e da fragmentação das disciplinas, de seus objetivos e de sua avaliação.

O currículo tradicional se caracteriza pelas unidades seguindo-se umas às outras em progressão linear, pelo caráter acumulativo, metódico, harmônico, disciplinado, com objetivos preestabelecidos, com preponderância da prática de exercícios intelectuais que visam robustecer a memória e capacitar o raciocínio e pela suposta neutralidade do conhecimento que veicula. Esse currículo está sendo gradualmente substituído por um currículo que se distingue pela ênfase na interdisciplinaridade, na consciência ecológica, na voz das minorias, na mudança não-violenta, na descentralização do processo decisório, na ética, no pluralismo cultural, no trabalho coletivo e na solidariedade. 


\section{Teorias que fundamentam a interdisciplinaridade e a transversalidade}

As mudanças nas concepções e práticas curriculares também vêm sendo respaldadas por algumas teorias educacionais, dentre as quais destacamos a teoria das inteligências múltiplas de Howard Gardner (1995), bastante conhecida na escola fundamental brasileira, e a teoria dos significados da vida humana de Philip Phenix (1960). As duas teorias se propõem retratar a totalidade do ser humano e, ao mesmo tempo, sua individualidade. Tenho realizado projetos temáticos com alunos de Licenciaturas, Pedagogia e de cursos de Especialização em Educação, e a utilização das duas teorias revelaram-se experiências muito enriquecedoras.

Phenix, já falecido, não teve oportunidade de reformular suas idéias, e, por isso, cabe a nós educadores, com o nosso saber prático, ensaiar de fazê-lo. Já Gardner, professor de Psicologia na Harvard Graduate School of Education, está em pleno vigor criativo, e, após a publicação do primeiro livro, Frames of Mind: The Theory of Multiple Intelligences (1983), onde identificou sete inteligências, incluiu a habilidade de desenhar como uma oitava, e no seu portal, ${ }^{2}$ acrescentou uma nona, a naturalista. Tem publicado sem parar a partir de 1983.

O que fez Gardner famoso entre os educadores foi sua crítica à concepção de que existe somente uma única inteligência humana e que esta deve ser avaliada por instrumentos psicometricamente padronizados. Acompanhando o desempenho profissional de adultos que haviam sido alunos fracos, Gardner se surpreendeu com o sucesso obtido por vários deles na vida real. O pesquisador passou, então, a questionar a avaliação escolar, cujos critérios não incluem a análise de capacidades, que, no entanto, são importantes na vida das pessoas. Concluiu que as formas convencionais de avaliação apenas traduzem a concepção de inteligência vigente na escola, limitada à valorização da competência lógico-matemática e da lingüística. Gardner demonstrou que as demais faculdades também são produto de processos mentais e que não há motivo para diferenciá-las do que geralmente se considera inteligência. Desta forma, ampliou o conceito de inteligência, que, em sua opinião, pode ser definida como "a capacidade de resolver problemas ou elaborar produtos valorizados em um ambiente cultural ou comunitário".

Segundo Gardner, excetuando-se os casos de lesões, todos nascem com o potencial das várias inteligências. A partir das relações com o ambiente, incluindo os estímulos culturais, desenvolvemos mais algumas e deixamos de aprimorar outras. Isso dá a cada pessoa um perfil particular, o que renega a possibilidade de medirmos a inteligência pelos métodos convencionais, principalmente pelos famosos testes de Q. I. (quociente de inteligência), que consideram apenas as manifestações das competências lógico-matemático e lingüística. Nos últimos quinze anos ele vem trabalhando com seus colegas num projeto educacional visando à criação de mecanismos de avaliação voltados ao desempenho integrado do educando e ao uso das inteligências múltiplas no planejamento e desenvolvimento de um currículo mais personalizado. Esse grupo de pesquisadores lançou o Projeto Bom Trabalho, no qual o conceito de bom trabalho abrange não só a qualidade do conteúdo, mas também suas implicações e aplicações. Além disso, o grupo começou também um estudo de instituições e currículos interdisciplinares.
$<$ http://www.chariho.k12.ri.us/ curriculum/MISmart/ MImapDef.HTM $>$. Neste endereço podemos encontrar uma belafigura representandooespectro das inteligências múltiplas.

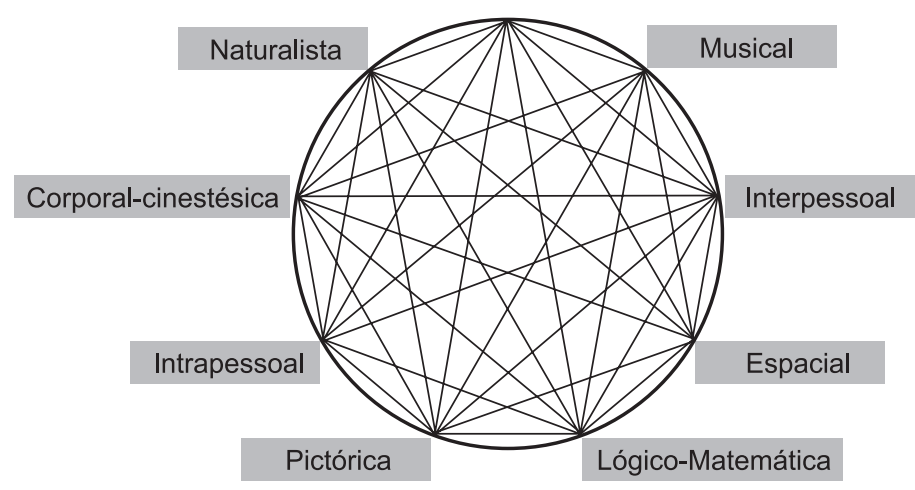

Figura 1 - Espectro de inteligências 
- Lingüística: manifesta-se na habilidade para lidar criativamente com as palavras nos diferentes níveis da linguagem (semântica, sintaxe), tanto na formal como na escrita, no caso de sociedades letradas. Particularmente notável nos poetas e escritores, oradores, jornalistas, vendedores.

- Lógico-matemática: é a inteligência que determina a habilidade para raciocínio dedutivo, além da capacidade para solucionar problemas envolvendo números e demais elementos matemáticos. É a competência mais diretamente associada ao pensamento científico, portanto, à idéia tradicional de inteligência.

- Pictórica: é a faculdade de reproduzir, pelo desenho, objetos e situações reais ou mentais, de organizar elementos visuais de forma harmônica, estabelecendo relações estéticas entre elas. Comum nos pintores, artistas plásticos.

- Musical: é a inteligência que permite a alguém organizar sons de maneira criativa, a partir da discriminação de elementos como tons, timbres e temas. As pessoas dotadas desse tipo de inteligência geralmente não precisam de aprendizado formal para exercê-la, como é o caso de muitos famosos da música popular brasileira.

- Intrapessoal: é a competência de uma pessoa para conhecer-se e estar bem consigo mesma, administrando sentimentos e emoções em favor de seus projetos; característica dos indivíduos "bem resolvidos", como se diz na linguagem popular.

- Interpessoal: é a capacidade de uma pessoa de se dar bem com as demais, compreendendo-as, percebendo suas motivações e sabendo como satisfazer suas expectativas emocionais. São os indivíduos de fácil relacionamento pessoal, como líderes de grupos, políticos, terapeutas, professores e animadores de espetáculos.

- Espacial: é a capacidade de formar um modelo mental preciso de uma situação espacial e utilizar esse modelo para orientar-se entre objetos ou transformar as características de um determinado espaço. Ela é especialmente desenvolvida, por exemplo, em arquitetos, navegadores, pilotos, cirurgiões, engenheiros e escultores.
- Corporal-cinestésica: é a inteligência que se revela como uma especial habilidade para utilizar o próprio corpo de diversas maneiras; envolve tanto o autocontrole corporal quanto a destreza para manipular objetos. Atletas, dançarinos, malabaristas e mímicos têm essa inteligência desenvolvida (Machado, 1996).

- Naturalista: a habilidade de distinguir os seres vivos assim como a sensibilidade a outros aspectos da natureza. Esta é, até o momento, a última inteligência agregada ao espectro.

As linhas internas na Figura 1, sugeridas por Machado (1996, p. 108), demonstram a interdependência das várias inteligências. Todas necessitam da linguagem: a música precisa das notas, das representações dos compassos, ritmos e de alguém que a execute; a matemática expressa-se em números, símbolos e letras; ao comunicarmo-nos uns com os outros, exprimimo-nos não só através de palavras mas também por gestos corporais, desenhos. No âmbito do interpessoal e intrapessoal, tudo indica que, se a pessoa está bem consigo mesma, consegue, através da linguagem, se relacionar melhor com os outros. Em nossa relação com a natureza (inteligência naturalista) incluímos sentimentos, atitudes verbais, corporais, pictóricas. Com nosso corpo, ocupamos um espaço que ninguém mais pode ocupar e, ao movimentarmonos, ampliamos este espaço, mas sempre tendo que levar em consideração que ele acaba quando começa o do outro. Temos características corporais comuns como seres humanos, mas também impressões digitais e fisionomias totalmente diferentes uns dos outros. Enfim, podemos ir relacionando um tipo de inteligência com o outro até formarmos uma intricada rede na qual é impossível determinar onde começam e onde acabam os domínios de cada inteligência.

Gardner estabeleceu vários critérios para que uma inteligência seja considerada como tal, desde sua possível manifestação em todos os grupos culturais até a localização de sua área no cérebro. Sempre envolvemos mais de uma habilidade na solução de problemas, embora existam predominâncias; portanto, as inteligências se integram.

São inúmeras as possíveis contribuições de uma teoria como a de Gardner para a prática escolar, sendo talvez a mais importante delas a concepção de que a escola deve ser modelada de forma a atender as diferenças 
entre os alunos e não tentar homogeneizálos. Tive a chance de orientar Trabalhos de Conclusão de Curso, tanto da graduação quanto da pós-graduação, que aplicaram a teoria das inteligências múltiplas nos mais diversos contextos na escola e que acabaram por provar sua utilidade. Destaco um deles, o das alunas Diolina Cristina Enéas Ferreira e Patrícia Izabel da Silva (curso de Pedagogia - Unicep-São Carlos), ambas professoras da Apae-São Carlos, que analisaram como o desenvolvimento da habilidade musical estimula as outras inteligências em crianças de idade entre 3 meses e 13 anos com necessidades especiais. Ao adaptar a teoria de Gardner para casos de lesões graves onde a linguagem verbal está extremamente comprometida, Diolina e Patrícia concluíram que, através da atenção especial ao desenvolvimento da inteligência musical, é possível exercitar a capacidade de ouvir, desenvolver o ritmo, despertar a sensibilidade, movimentar o corpo, estimular a percepção, a atenção, a concentração, a memória e propiciar a socialização, integração e sensibilização ao estético.

Philip H. Phenix, professor emérito de Filosofia e Educação do Teachers College (Universidade de Columbia), doutourou-se em Filosofia da Religião. Dentre os vários livros que escreveu, a maioria versando sobre a integração das disciplinas, destaca-se Realms of Meaning (1964), onde ele apresenta a teoria dos significados da vida humana.

$\mathrm{O}$ argumento principal de Phenix (1964) é que uma visão de currículo para a educação geral deve ser derivada de certas considerações fundamentais sobre a natureza humana e o conhecimento. A vida humana consiste num padrão de significados, e a educação geral é o processo de gerar significados essenciais. Os seres humanos são essencialmente criaturas que têm o poder de experienciar significados. A existência humana consiste num padrão de significados. A educação geral é o processo de gerar significados essenciais, entretanto esta capacidade está sempre ameaçada: primeiro, pelo espírito crítico e céptico da herança científica; segundo, pela despersonalização e fragmentação da vida causada pela extrema especialização de uma sociedade complexa e interdependente; terceiro, pela massa de produtos culturais, especialmente de conhecimentos, que o homem moderno tem que assimilar; e quarto, pela rapidez com que as condições da vida humana mudam, resultando num sentimento de impermanência e insegurança. Sendo o objetivo da educação levar ao preenchimento da vida humana mediante o alargamento e aprofundamento do significado, o currículo moderno deve ser planejado com particular atenção para estas fontes de perda do significado da vida moderna.

Muitos seguem uma carreira limitada sem pensar em seu papel no cenário total da civilização. Essa visão limitada é evidente na educação e, para adquirirmos uma perspectiva integral, precisamos de uma filosofia do currículo que dê conta da totalidade e da individualidade do ser humano - e esse equilíbrio é fundamental. Levinas (1982 e 1988) nos adverte para o que ele chama de nostalgia da totalidade (1982, p. 68), em que o espiritual e o significativo residem sempre no saber. A história da filosofia pode ser interpretada como uma tentativa de síntese universal, uma redução de toda a experiência, de tudo aquilo que é significativo a uma totalidade em que a consciência abrange o mundo, não deixando nada fora dela, tornandose assim pensamento absoluto. É a consciência de si ao mesmo tempo que consciência do todo. Entretanto, há coisas não-sintetizáveis. Essa visão globalizante que caracteriza os grandes sistemas filosóficos é somente desafiada pela relação com o Outro, pela Ética e pela Moral. " A experiência irredutível e última da relação parece-me, de fato, estar noutra parte: não na síntese, mas no frente a frente dos humanos, na sociedade, no seu significado moral." (p. 68-69). O não-sintetizável, portanto, é a relação entre os homens.

Sendo o objetivo da educação levar ao preenchimento da vida humana através do alargamento e aprofundamento do significado, o currículo deve ser planejado com particular atenção para as fontes de perda do significado da vida moderna.

Uma filosofia do currículo é importante por várias razões, entre elas Phenix cita:

- uma visão compreensiva é necessária em todas as decisões sobre o que incluir e o que excluir do currículo. Se uma matéria é escolhida em detrimento de outra, é importante saber como uma difere da outra e porque uma foi preferida para figurar na configuração completa da experiência e do caráter do aluno; 
- desde que a pessoa é essencialmente uma totalidade organizada e não somente uma coleção de partes separadas, o currículo também deve ter uma qualidade orgânica correspondente;

- a sociedade, assim como os indivíduos, depende de princípios de comunidade. Um currículo compreensivo contribui como base para o crescimento do espírito de comunidade, enquanto que um programa de estudos atomizado produz a desintegração na vida social;

- uma concepção compreensiva da estrutura da aprendizagem valoriza cada um dos segmentos que compõem o currículo. O significado de cada disciplina é engrandecido pela compreensão das relações com outras disciplinas, e seus elementos distintivos são melhor compreendidos à luz das similaridades e contrastes com as outras áreas (Phenix, 1964, p. 4).

São seis os padrões fundamentais, os domínios do significado: simbólico, empírico, estético, sinoético, ético e sinóptico. Cada domínio de significado e cada um dos subdomínios pode ser descrito com referência ao seu método típico, idéias condutoras e estruturas características.

O domínio simbólico compreende a linguagem comum, a matemática e várias outras formas simbólicas não discursivas, como gestos, rituais, padrões rítmicos, etc. Estes significados estão contidos nas estruturas simbólicas arbitrárias com regras socialmente aceitas de formação e transformação, criadas como instrumentos para a expressão e comunicação de qualquer significado.

O segundo domínio, o empírico, inclui as ciências do mundo físico, das coisas vivas, e do homem. Estas ciências fornecem as descrições factuais, generalizações, formulações e explicações teóricas que são baseadas na observação e experimentação no mundo da matéria, vida, mente, e sociedade. Elas expressam significados como verdades empíricas prováveis estruturadas de acordo com certas regras de evidência e verificação e fazendo uso de sistemas específicos de abstração analítica.

O terceiro domínio, o estético, contém as várias artes - a música, as artes visuais, as artes do movimento - e a literatura. Os significados nos domínio relacionam-se com a percepção contemplativa de coisas particulares significativas como objetivações únicas das subjetividades idealizadas.

O quarto domínio, o sinoético, engloba o"conhecimento pessoal". O termo "sinoético" deriva do grego "synnoesis" (syn = com; noesis = cognição), significando pensamento meditativo, "insight" relacional, compreensão direta. É análogo na esfera do conhecimento à simpatia na esfera do sentimento. Este conhecimento é concreto, direto e existencial. Pode aplicar-se a outras pessoas, a si mesmo, ou mesmo a coisas.

O quinto domínio, o da ética, inclui significados morais que expressam obrigação em vez de fato, formas perceptuais, ou compreensão de relação - em contraste com as ciências, que se preocupam com a compreensão abstrata cognitiva, com as artes, que expressam percepções estéticas idealizadas, e com o conhecimento pessoal, que é baseado na decisão livre, responsável, deliberada.

O sexto domínio, sinóptico, refere-se aos significados que são compreensivelmente integrativos; inclui história, religião, e filosofia. Estas disciplinas integram significados empíricos, estéticos e sinoéticos em todos coerentes. A interpretação histórica compreende uma recriação artística do passado, em obediência à evidência factual, com o propósito de revelar o que o homem fez de si próprio dentro do contexto de certas circunstâncias. A Religião relaciona-se com os significados últimos, isto é, com significados de qualquer domínio, considerados do ponto de vista de tais conceitos como o Todo, o Compreensivo, e o Transcendente. A filosofia fornece uma clarificação analítica, avaliação e coordenação sintética de todos os outros domínios por meio da interpretação conceitual de todos os possíveis tipos de significado na sua distinção e nas suas inter-relações.

O simbólico, que foi colocado no fim do espectro, engloba todo o âmbito dos significados, porque é a via de expressão de todos os significados. O sinóptico, que foi colocado no outro final do espectro, também engloba todo o âmbito dos significados pela virtude integrativa de seu caráter.

Uma pessoa completa deve desenvolver habilidades no uso da fala, símbolo e gesto, estar factualmente bem informada, ser capaz de criar e apreciar objetos de significação estética, dispor de uma vida rica e disciplinada em relação a si mesma e a outras, ser capaz de tomar sábias decisões e de 
julgar o que é certo e o que é errado e ser possuidora de uma perspectiva integral. Estes são os objetivos da educação geral para o desenvolvimento da pessoa completa. Um currículo que desenvolva estas competências básicas deverá satisfazer as necessidades humanas de significado. Instrução em linguagem, matemática, ciência, arte, relações pessoais, moral, história, religião e filosofia constituem a resposta educacional para o espírito destrutivamente crítico e para o difundido sentimento moderno de ausência de sentido.

As classes genéricas dos significados são obtidas combinando os três aspectos quantitativos com os três aspectos qualitativos.

\section{Quadro 1 - Classificação lógica dos significados}

\begin{tabular}{|c|c|c|}
\hline \multicolumn{3}{|c|}{ Classes Genéricas Reinos de Disciplinas } \\
\hline Quantidade & Qualidade & Significados \\
\hline Geral & Forma Simbólico & Linguagem comum, matemática, formas simbólicas não-discursivas. \\
\hline Geral & Fato Empírico & Ciências físicas, ciências da vida, psicologia, ciências sociais. \\
\hline Singular & Forma Estético & Música, artes visuais, artes do movimento, literatura. \\
\hline Singular & Fato & $\begin{array}{l}\text { Sinoético | Filosofia, psicologia, literatura, religião nos seus aspectos } \\
\text { existenciais. }\end{array}$ \\
\hline Singular Geral & Norma & Ético | As várias áreas especiais do campo moral e ético. \\
\hline Compreensivo & Fato & Sinóptico | História \\
\hline Compreensivo & Norma & Religião \\
\hline Compreensivo & Forma & Filosofia \\
\hline
\end{tabular}

Nota: Adaptado de Phenix, P. (1964) Realms of Meaning. New York: Mc Graw Hill،

- Forma geral. Esta classe inclui as disciplinas que se preocupam com a elaboração dos padrões formais para aplicação geral na expressão dos significados: o reino do simbólico.

- Fato geral. Conhecimento da província da ciência: o reino do empírico.

- Forma singular. Significados percebidos pela imaginação sem nenhuma referência aos fatos reais: o reino do estético.

- Fato singular. Significados originados da existência concreta em encontro pessoal: sinoético, ou seja, a filosofia, a religião e a psicologia.

- Norma singular. O reino das obrigações morais.

- Norma geral. A ética; distingue-se da norma singular pela qualidade da obrigação. Os métodos e categorias da ética social, por exemplo, diferem daqueles da ética pessoal.

- Fato compreensivo. O historiador integra o simbólico, o empírico, o estético e o ético em uma perspectiva sinóptica sobre o que aconteceu no passado.

- Norma compreensiva. Quando todos os tipos de conhecimento são compreendidos dentro de uma perspectiva sinóptica controlado pela qualidade normativa, a disciplina resultante é a religião.

- Forma compreensiva. O reino do filosófico.

Como então podemos possibilitar, em nossa prática pedagógica, o desenvolvimento das várias inteligências e/ou dos vários significados da vida humana, para que o aluno se insira no contexto pós-moderno, onde a informação circula numa velocidade avassaladora, onde ele tem de buscar o conhecimento por si mesmo, a trabalhar em grupo e, ao mesmo tempo, desenvolver suas habilidades individuais? Uma das maneiras que nos é apresentada é a pedagogia de projetos.

O projeto tece uma teia de significados e relações entre as disciplinas, entre os conteúdos e o contexto, entre professores e seus pares, entre alunos e professores e entre alunos e seus pares. O projeto possibilita o desenvolvimento das habilidades individuais e, ao mesmo tempo, articula essa individualidade com o coletivo. Ao realizar um projeto individual dentro de um projeto coletivo, o homem 
relaciona-se consigo mesmo e com os outros homens. A idéia de projeto situa-se no mundo do trabalho produtivo, excluindo, portanto, o trabalho alienado (Kleiman; Moraes, 1999).

No início do semestre, apresento geralmente as duas teorias - a das inteligências múltiplas e a dos significados da vida humana - e peço aos alunos que escolham com qual preferem trabalhar. Geralmente as classes se dividem entre as duas teorias. Para exemplificar, escolhi três projetos que utilizaram a teoria de Phenix, por ser menos conhecida na escola brasileira. ${ }^{3}$

Dividimos a classe em grupos de seis (os seis significados) e de nove (as nove inteligências). De preferência reúnem-se grupos com representantes de todas as áreas, algo mais possível nas Licenciaturas. Os temas são escolhidos a partir de revistas de circulação semanal, jornais e livros, levados para a sala de aula por mim e pelos próprios alunos. Eles folheiam o material, comentam entre si quais assuntos lhes chamaram a atenção. Cada grupo deve chegar a um consenso com relação ao tema a ser abordado, aos objetivos e à justificativa de cada projeto. Divide-se o trabalho de tal forma que cada aluno se encarregue de pensar, planejar e apresentar um significado ou uma inteligência dentro do tema escolhido. Os projetos são apresentados ao grande grupo (a classe toda) e avaliados de acordo com critérios discutidos mais ou menos no terceiro encontro, quando cada grupo já está bem envolvido com o tema. Os critérios de avaliação constam de uma ficha (modelo abaixo) que cada aluno recebe durante as apresentações dos projetos (ao final de mais ou menos cinco encontros).
Meu intuito de colocar a teoria para ser analisada e experimentada pelo grande grupo de alunos não é somente o de informá-los sobre dois autores tão significativos no cenário educacional e/ou ensiná-los a trabalhar em grupo e/ou fazê-los pensar em como aliar teoria e prática. Tenho objetivos bem mais interesseiros: quero também ver se a teoria realmente funciona na prática; quais suas falhase como preencher as lacunas; como as pessoas trabalham em grupo; se as soluções encontradas para os problemas que surgem podem de fato ser fruto de um consenso e como se chega a este consenso; se é possível haver o tão apregoado diálogo entre disciplinas (essa parte é melhor testada nas Licenciaturas); se o projeto realmente desperta sentimentos de solidariedade e cooperação; como funciona uma avaliação coletiva; enfim, uso as aulas como laboratório de minha própria pesquisa. Os alunos são devidamente informados de tais objetivos e até hoje ninguém reclamou, pois o lucro é mútuo. Temos projetos riquíssimos versando sobre os mais diversos temas, tais como, Água, Lixo, Imigração, Colonização, Super-Heróis, Energia, Aids, Drogas, Violência, e os resultados vêm sendo encorajadores.

Apresento abaixo três projetos recentes realizados por professores de escolas públicas, alunos do curso de Pedagogia do Unicep - São Carlos. A figura mostra apenas os tópicos iniciais do planejamento, e as reticências indicam justamente que não se prevê o que pode ser inserido em cada quadro, pois vai depender das contribuições de todos os envolvidos. As apresentações orais dos projetos são bem mais enriquecedoras, pois as pessoas podem adiantar alguns passos, hipóteses e possibilidades, mas, olhando a figura, esperamos que o leitor preencha algumas reticências.

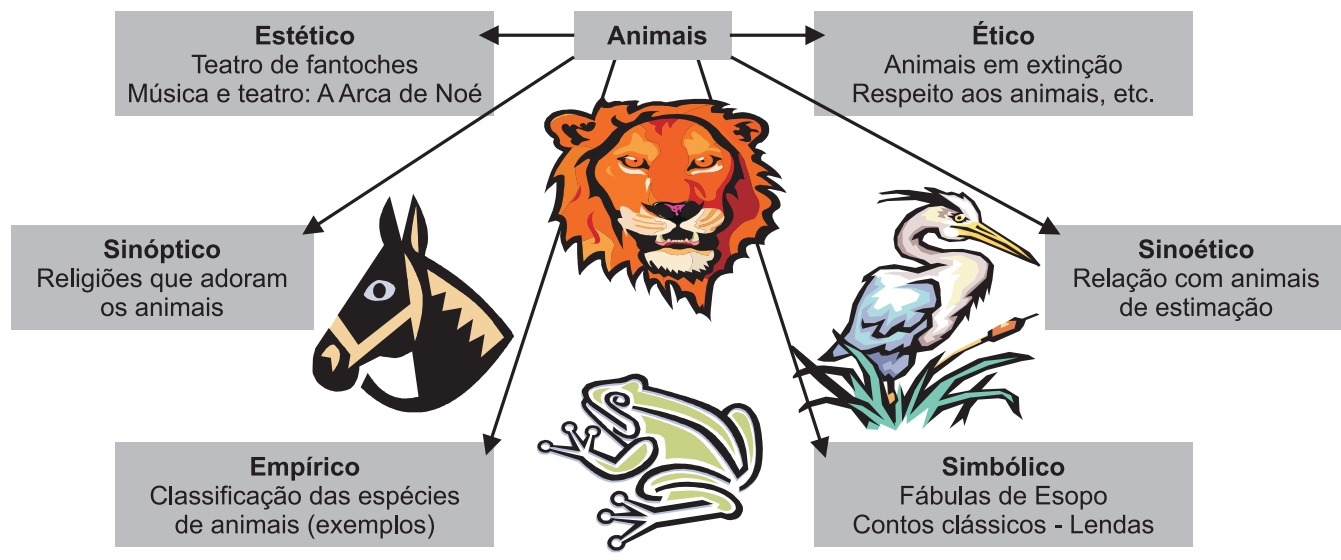

Figura 2 - Projeto Animais (para crianças de $1^{\mathrm{a}}$ a $4^{\mathrm{a}}$ série)

\footnotetext{
3 Em minha pesquisa de doutorado (Unicamp, 1995), analisei o Bacharelato Internacional (IB), um currículo desenvolvido por escolas internacionais à luz dos significados da vida humana. O trabalho de campo foi realizado na Escola Americana de São Paulo, e a tese intitulou-se $O$ Currículo do Diálogo.
} 


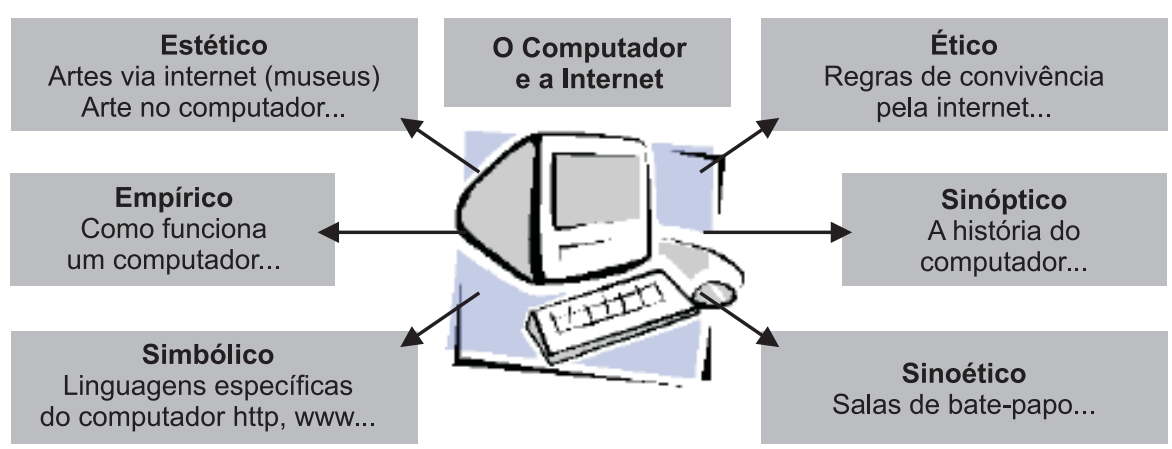

Figura 3 - Projeto O Computador e a Internet (de $5^{\mathrm{a}}$ a $8^{\mathrm{a}}$ série)

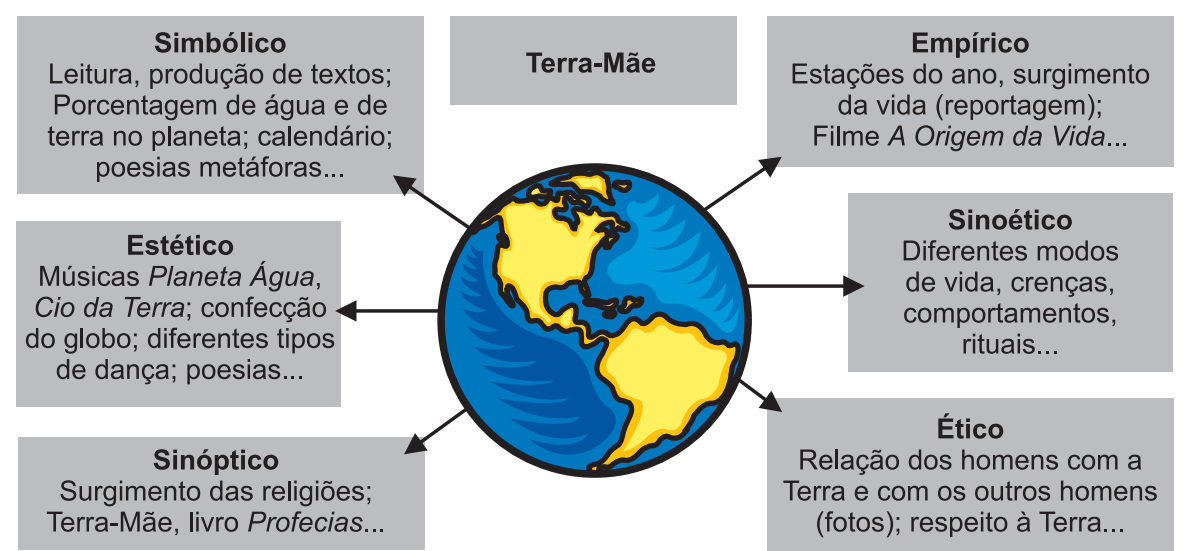

Figura 4 - Projeto Terra-Mãe (de $5^{\mathrm{a}}$ a $8^{\mathrm{a}}$ série e Ensino Médio)

Modelo A

(continua)

(Apresentação de 30 minutos com 10 minutos para perguntas)

Nome do avaliador:

Tema do projeto:

\begin{tabular}{|l|l|l|}
\hline ASPECTOS A AVALIAR & PESO \\
\hline 1. Domínio do simbólico \\
\hline 2. Domínio do empírico \\
\hline 3. Domínio do ético \\
\hline 4. Domínio do sinoético \\
\hline 5. Domínio do sinóptico \\
\hline 6. Domínio do estético \\
\hline 7. Coerência e Clareza \\
\hline 8. Organização \\
\hline 9. Participação e Integração \\
\hline 10. Domínio do assunto \\
\hline Total \\
\hline
\end{tabular}

Figura 5 - Fichas de avaliação dos projetos temáticos (Modelo A) 
Nome do avaliador:

Tema do projeto:

\begin{tabular}{|l|l|}
\hline ASPECTOS A AVALIAR & PESO \\
\hline 1. Domínio do simbólico \\
\hline 2. Domínio do empírico \\
\hline 3. Domínio do ético \\
\hline 4. Domínio do sinoético \\
\hline 5. Domínio do sinóptico \\
\hline 6. Domínio do estético \\
\hline 7. Coerência \\
\hline 8. Organização \\
\hline 9. Divisão do tempo \\
\hline 10. Coerência \\
\hline Total \\
\hline
\end{tabular}

Figura 5 - Fichas de avaliação dos projetos temáticos (Modelo B)

As fichas diferem nos últimos tópicos, porque estes são os aspectos que cada classe escolhe por meio de propostas e votação: são 6 critérios fixos e 4 móveis, no caso da teoria do Phenix, mas se estivermos usando as inteligências múltiplas, então os elementos fixos são nove. Com base em discussão, também se atribui um peso para cada item. A nota final é o resultado da média aritmética de todas as fichas. O professor também dá uma nota baseada numa ficha, e cada aluno se autoavalia; portanto, a avaliação final baseiase na nota do grande grupo, na nota do professor e na auto-avaliação. Pretende-se com isso chegar a uma avaliação mais justa: que seja fruto de um consenso, que dê margem à crítica e autocrítica e que supere a visão de que o professor é o único juiz legítimo do desempenho do aluno. Em muitos casos, o método de avaliação acadêmica e comportamental pouco se diferencia da palmatória - é o velho conceito de disciplina e obediência, que gera passividade e subserviência. Em suma, propomos uma avaliação em que:

- os critérios sejam discutidos previamente, o que imprime ao processo um caráter de jogo aberto e limpo, sem truques e nem surpresas;

- os alunos se auto-avaliem, dando conta do aspecto individual;
- a classe toda avalie o trabalho de cada grupo, atribuindo um caráter coletivo à avaliação;

- a avaliação do professor seja apenas uma das avaliações às quais o aluno é submetido. ${ }^{4}$

\section{Considerações finais}

Os projetos interdisciplinares têm a grande vantagem de dar espaço à iniciativa e à criatividade dos participantes. Além disso, estimulam o espírito coletivo, a solidariedade e a troca de informações, contribuindo decisivamente para a construção do conhecimento. O professor, quando necessário, deve induzir, sugerir temas que despertem o interesse do aluno e que sejam de relevância no sentido social, cultural e econômico. Não podemos deixar que os temas sejam decididos apenas pelos alunos, pois nós, professores, temos a obrigação de ampliar seus horizontes de interesses. ${ }^{5}$

Há certos conteúdos disciplinares que não se enquadram em nenhum projeto. É necessário, repetimos, que sejam resguardadas as fronteiras entre as disciplinas e que haja momentos quando as classes trabalhem tanto individual quanto disciplinarmente. A instância para o planejamento dos projetos interdisciplinares é o Horário de

\footnotetext{
${ }^{4}$ Quanto ao último aspecto, há Quanto ao último aspecto, há atribuíram maior peso à avaliação do professor, outras que decidiram que a avaliação do professor devia ter o mesmo peso que a de qualquer aluno, ehouve até uma classe de licenciatura em Ciências Exatas que eliminou por completo a avaliação do professor. Neste último caso, não investiguei a fundo as causas de tal trauma: os alunos me contaram que, em alguns cursos deCiências Exatas, as avaliacõos são bem mais duras. Pareceu-me que nesta classe, por acaso, estavam presentes algumas "vítimas" de processos avaliativos bem traumatizantes.

5 Soube do caso de uma professora de uma escola de Brotas (SP) que deixou os alunos decidirem o tema do projeto, e eles escolheram a vida do cantor Daniel (natural da cidade). Por mais que este seja considerado um personagem no cenário nacional, não pode ser visto como tema de relevância sociocultural a ponto de fazer parte do currículo escolarfundamental.
} 
Trabalho Pedagógico Coletivo (HTPC), oportunidade única para trocar idéias, integrar. No âmbito do aluno, o projeto interdisciplinar desenvolvido em sala de aula dá-lhe a oportunidade de construir seu próprio conhecimento e de se desenvolver como cidadão crítico, solidário e participativo.

Um currículo que favoreça os projetos deixa o professor bastante livre, mas, ao mesmo tempo, repousa sobremaneira na sua habilidade como educador. Se não houver, por parte da escola, investimento na capacitação e condições de trabalho do corpo docente, o resultado é um fracasso. Quanto ao aluno, desde que ele é convidado a participar da construção do currículo, desenvolve uma capacidade crítica bem mais aguçada, o que lhe dá condições de questionar, mas, para que isso ocorra, é necessário dar espaço à divergência. Alunos passivos são formados por meio da memorização de conteúdos vazios, autoritários e prontos. As bases do autoritarismo numa escola estão desde a arrumação das carteiras (todas enfileiradas de frente para o professor, com os alunos olhando um para a nuca do outro) até a avaliação. O projeto temático exclui tais mecanismos despóticos, pois os alunos têm de trabalhar em grupo, muitas vezes em espaços externos à sala de aula, $\mathrm{e}$ participam ativamente do planejamento, desenvolvimento e avaliação do projeto.

O excessivo individualismo, o egoísmo, é neutralizado na pedagogia de projetos pela sua característica fundamental de inclusão do Outro. Levinas (1988), Doll (1999), Bernstein (1992), Dussel (s/d) já nos vêm advertindo sobre a tendência contemporânea de reduzir ou assimilar o Outro ao Mesmo, especialmente no terreno cultural. Vemos o currículo como um espaço de resistência a tal violência. Na educação, e principalmente na avaliação, a preocupação principal ainda é a comparação com um padrão determinado (por quem?), e, nesse processo, o criativo, o inesperado, se perde: é a vitória do Mesmo sobre o Outro. Entretanto, num projeto, tanto o similar quanto a alteridade são respeitados. No início não sabemos exatamente como e com que cada um vai contribuir e qual vai ser o produto coletivo final. O planejamento serve para estabelecermos linhas gerais, condições iniciais, possibilidades. Essa característica de imprevisibilidade produz uma sensação de desafio e liberdade. Geram-se frutos dos indivíduos e do coletivo, onde cada um se reconhece e, ao mesmo tempo, há partes (ou momentos) que não permitem separar os componentes.

Para finalizar, não podemos deixar de considerar que todas estas teorias trazem concepções que são construções sociais e não verdades absolutas, e, assim como estamos transformando o currículo com o intuito de nos descartar pressupostos da modernidade considerados obsoletos e insatisfatórios, assim também estamos sujeitos a mudanças, às vezes radicais, tanto na ciência quanto em nossas visões de mundo, e, conseqüentemente, temos de mudar também o currículo. Uma teoria filosófica pretende transcender fronteiras e penetrar no âmago da existência, mas ela é formulada por um ser humano que, embora pensador penetrante, é condicionado pelo seu contexto cultural, sexual, racial e político. Para que uma teoria seja realmente de utilidade para a compreensão e o desenvolvimento curricular, é preciso que ela seja submetida à experimentação, adaptação e avaliação daqueles envolvidos no processo de aprendizagem. Portanto, a visão de currículo defendida por este artigo consiste numa construção conjunta, fruto de intensa negociação e do consenso entre os participantes, e que seja suficientemente flexível, a fim de conter em si a eterna semente da mudança.

\section{Referências bibliográficas}

APPLE, M. On analyzing hegemony. In: GIROUX, H.; PENNA, A.; PINNAR, W. Curriculum and Instruction. California: McCutchan Publ. Corp., 1981a.

Official Knowledge: democratic education in a conservative age. New York:

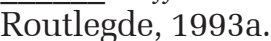


APPLE, M. The politics of Official Knowledge: does a national curriculum make sense? Teachers College Record, v. 95, n. 2, p. 222-241, 1993b.

BERNSTEIN, R. The new constellation. Cambridge, MA: MIT Press, 1992.

BOURDIEU, P.; PASSERON, J. C. A reprodução. Rio de Janeiro: Francisco Alves, 1982.

DOLL JR., W. E. Conversing with "the Other". Journal of Curriculum Theorizing, v. 15, n. 3, 1999.

DUSSEL, E. Filosofia da Libertação (Filosofia na América Latina). São Paulo: Loyola, [s.d.]

FEATHERSTONE, M. Da Universidade à pós-universidade? Explorando as possibilidades de novas formas de comunicação. In: MORAES, S. E.; SANTOS FILHO, J. C. (Org.). Escola e Universidade na pós-modernidade. Campinas: Mercado de Letras, 2000.

FERREIRA, D. C. E.; SILVA, P. I. A Música como recurso pedagógico para crianças portadoras de necessidades especiais. Trabalho de Conclusão de Curso, Pedagogia, Unicep São Carlos, 2003.

GARDNER, H. Changing minds: the art and science of changing your own and other people's minds. Harvard Business School Press, 2004.

1983.

. Frames of mind: the theory of multiple intelligences. New York: Basic Books, Inteligências múltiplas: a teoria na prática. Porto Alegre: Artmed, 1995.

$\overline{\text { Books, }} 1999$.

Intelligence reframed: multiple intelligences for the 21st century. New York: Basic

. Multiple intelligences: the theory in practice. New York: Basic Books, 1993.

. The unschooled mind: how children think and how schools should teach. New York: Basic Books, 1991.

GARDNER, H.; LASKIN, E. Leading minds: the anatomy of leadership. New York: Basic Books, 1995. 1996.

. Mentes que lideram: uma anatomia da liderança. Porto Alegre: Artes Médicas,

GLEISER, M. Uma lição de humildade cósmica. Folha de S. Paulo, 22 mar. 1998. Micro/ Macro.

GOERGEN, P. A crise de identidade da universidade moderna. In: MORAES, S. E.; SANTOS FILHO, J. C. (Org.). Escola e Universidade na pós-modernidade. Campinas: Mercado de Letras, 2000.

HABERMAS, J. Entrevista dada à Barbara Freitag e Sérgio Paulo Rouanet. Folha de S. Paulo, 30 maio, 1995. Caderno Mais!

. (1983) Modernity: an incomplete project. In: FOSTER, H. (Ed.). The anti-esthetic: $\overline{\text { essays }}$ in post-modern. Washington: Post Townsend, 1985.

. The theory of communicative: reason and the rationalization of society action. Translated by Thomas McCarthy. Boston: Beacon Press, 1984. v. 1. 
HARVEY, D. Condição Pós-Moderna. Trad. Adail Ubirajara Sobral e Maria Stela Gonçalves. São Paulo: Edições Loyola, 1994.

KLEIMAN, A.; MORAES, S. E. Leitura e Interdisciplinaridade: tecendo redes nos projetos da escola. Campinas: Mercado de Letras, 1999.

LEVINAS, E. Ética e Infinito-diálogos com Philippe Nemo. Lisboa: Edições 70, 1982.

. Totalité et Infini: essai sur l'exteriorité. Dordrecht, The Netherlands: Kluwer Academic Publishers, 1988.

MACHADO, N. J. Epistemologia e didática: as concepções do conhecimento e inteligência e a prática docente. São Paulo: Cortez, 1996.

MORAES, S. E. Currículo, transversalidade e pós-modernidade. In: MORAES, S. E.; SANTOS FILHO, J. C. (Org.). Escola e Universidade na pós-modernidade. Campinas: Mercado de Letras, 2000.

. In search of a vision: how brazil is struggling to envision citizenship for its public schools. In: PINAR, W. (Ed.). International Handbook of Curriculum Research. Mahwah, NJ: Lawrence Erlbaum Associates, 2003a.

. E. Habermas e a ação comunicativa na escola. In: MACHADO, N.; CUNHA, M. (Org.). Linguagem, conhecimento, ação: ensaios de epistemologia e didática. São Paulo: Ed. Escrituras, 2003b. (Série Ensaios Transversais ; v. 3).

MORAES, S. E.; SANTOS FILHO, J. C. (Org.). Escola e Universidade na pós-modernidade. Campinas: Mercado de Letras, 2000.

PHENIX, P. Philosophies of Education. John Wiley \& Sons Inc., 1961.

. Realms of Meaning: a philosophy of the curriculum for general education. NewYork: McGraw Hill Book Company, 1964.

. Education and the common good: a moral philosophy of the curriculum. Greenwood Press, 1977.

SANTOS FILHO, J. C. Universidade, modernidade e pós-modernidade. In: MORAES, S. E.; SANTOS FILHO, J. C. (Org.). Escola e Universidade na pós-modernidade. Campinas: Mercado de Letras, 2000.

TOULMIN, S. The Return to Cosmology. Berkeley: University of California Press, 1982.

TOURAINE, A. Crítica da Modernidade. Petrópolis: Vozes, 1995.

Silvia Elizabeth Moraes, doutora em Administração Educacional pela Universidade Estadual de Campinas (Unicamp), com pós-doutorado na Faculdade de Educação da Universidade de São Paulo (USP), é professora do Centro Universitário Central Paulista (Unicep-São Carlos)/Universidade Federal do Ceará (UFC). silviamoraes@secrel.com.br 


\section{Abstract Interdisciplinarity and transversality by means of thematic projects}

This paper suggests the practice of interdisciplinarity and transversality in elementary schools through thematic projects. Interdisciplinarity is seen as an epistemological approach to knowledge that questions the disciplinary, fragmented vision of knowledge. Transversality refers to a pedagogic approach that helps the student acquire a more comprehensive and critical vision of reality as well as his/her insertion and participation in this reality. As the theoretical foundation for interdisciplinarity and transversality, we use Howard Gardner 's theory of Multiple Intelligences and Philip Phenix's theory of human life meanings. We also propose a form of evaluation constructed collectively by the participants of the thematic projects.

Keywords: interdisciplinarity; transversality; elementary school; thematic projects.

Recebido em 23 de dezembro de 2004.

Aprovado em 26 de agosto de 2005. 